\title{
ACUTE GRAFT-VERSUS-HOST DISEASE AFTER HUMAN HEART-LUNG TRANSPLANTATION: A CASE REPORT
}

\author{
R. Pfitzmann, MD, M. Hummel, MD, O. Grauhan, MD, P. Waurick, MD, R. Ewert, MD, M. Loebe, MD, \\ Y. Weng, MD, and R. Hetzer, MD, Berlin, Germany
}

The occurrence of acute and chronic graft-versus-host disease (GVHD) has been widely described in the literature, with nearly $50 \%$ of cases occurring after bone marrow transplantation. Acute GVHD in thoracic organ transplantation has been observed after experimental lung transplantation in animals ${ }^{1}$ but has not been recognized very often in lung and heart-lung recipients, ${ }^{2-5}$ although donor cells persist in the lungs for up to 6 weeks after the operation. Altogether we found only four publications with a total of six patients having acute GVHD after heart-lung transplantation worldwide.

We report on a 28-year-old woman with congenital ventricular septal defect and Eisenmenger reaction in whom acute GVHD developed on the tenth postoperative day after successful heart-lung transplantation. Immunosuppressive drug therapy was administered with cyclosporine, azathioprine, and steroids. Additionally, rabbit antithymocyte globulin was administered once at a dose of $1.5 \mathrm{mg} / \mathrm{kg}$ body weight for induction therapy. Blood products were not given before, during, or after transplantation.

The cytomegalovirus status of the donor and the recipient were negative. Human leukocyte antigen (HLA) match showed conformity of five HLA specificities. With the patient receiving sufficient immunosuppression, initial manifestations of acute GVHD were a temperature higher than $40^{\circ} \mathrm{C}$ and a maculopapular rash for the first days. Subsequent manifestations included hematopoietic dysfunction (aplastic syndrome) with leukopenia, anemia and low platelet count, hepatitis, cardiac irregularity with supraventricular and ventricular arrhythmias, and generalized central seizures after a few days. Echocardiographic findings (early diastolic relaxation time and myocardial wall thickness) and the intramyocardial electrocardiogram (IMEG) showed no signs of acute rejection. The concentrations of plasma transaminases, serum bilirubin, creatinine, lactate dehydrogenase, creatinine, and myoglobin were elevated to very high levels, whereas the number of red blood cells, leukocytes, and platelets decreased rapidly, indicating a severe course of unknown disease at that time. The skin rash rapidly progressed to a form resem-

From the Deutsches Herzzentrum Berlin, Berlin, Germany.

Received for publication Dec. 23, 1996; accepted for publication Jan. 24, 1997.

Address for reprints: R. Pfitzmann, MD, Deutsches Herzzentrum Berlin, Cardiac Surgery and Transplant Division, Augustenburger Platz 1, 13353 Berlin, Germany.

J Thorac Cardiovasc Surg 1997;114:285-7

Copyright (C) 1997 by Mosby-Year Book, Inc.

$0022-5223 / 97 \$ 5.00+0 \quad \mathbf{1 2 / 5 4 / 8 0 7 3 5}$ bling toxic epidermal necrolysis (Lyell syndrome). At this point we saw no evidence of localized or generalized viral, bacterial, or fungal infection. After the development of renal failure and acute shortness of breath, leading to a short period of cardiopulmonary resuscitation, continuous controlled mechanical ventilation was necessary. Because of progressive renal failure, the patient required hemodialysis. Diagnosis of acute GVHD was confirmed by clinical implications, skin biopsy from the area of cutaneous lesions, and evidence of more than $50 \%$ of donor-specific lymphocytes in peripheral blood by HLA typing. For therapy, additional immunosuppression with rabbit antithymocyte globulin at a dose of $2.5 \mathrm{mg} / \mathrm{kg}$ body weight and high-dose steroids were instituted. Although cutaneous and hematologic manifestations of acute GVHD improved during the following days, with augmented quadruple immunosuppressive drug therapy and transfusion of blood products for aplastic syndrome, the patient died on postoperative day 34 of intracerebral bleeding.

Acute GVHD may occur as a result of the infusion of blood products containing viable lymphocytes, but in this case the patient had not received any blood products at the time of manifestation of GVHD. Therefore, the viable lymphocytes were considered transplanted with the donor organs.

Acute GVHD in patients receiving thoracic organ transplants has been recognized rarely until now. Thus, in view of the worldwide increasing numbers of lung and heart-lung transplantation, acute GVHD, as yet uncommon, may become more important in the future.

The first manifestation of acute GVHD can be the development of fever and maculopapular rash, which is frequently mistaken for a viral or allergic rash. In due course the persistent rash begins to scale, and diarrhea, hepatosplenomegaly, jaundice, cardiac irregularity, central nervous system irritability, and pulmonary infiltrates may occur at the height of the acute GVHD.

Once acute GVHD is established, little can be done to modify its course. Corticosteroids merely serve to enhance the susceptibility to infection. Cytolytic therapy (antithymocyte globulin) is necessary to destroy donor lymphocytes. On the other hand, this therapy results in further suppression of immunity. Cyclosporine, a more specific immunosuppressive agent, can also be helpful. After solid organ transplantation, the appearance of acute GVHD is fatal in the majority of immunosuppressed patients. Because treatment is very difficult, immediate early diagnosis of acute GVHD appears to be essential to institute adequate and early therapy and to prevent the severe course of this disease, ultimately with the death of the patient.

When characteristic signs appear, such as fever and rash, acute GVHD should be considered a possible diag- 


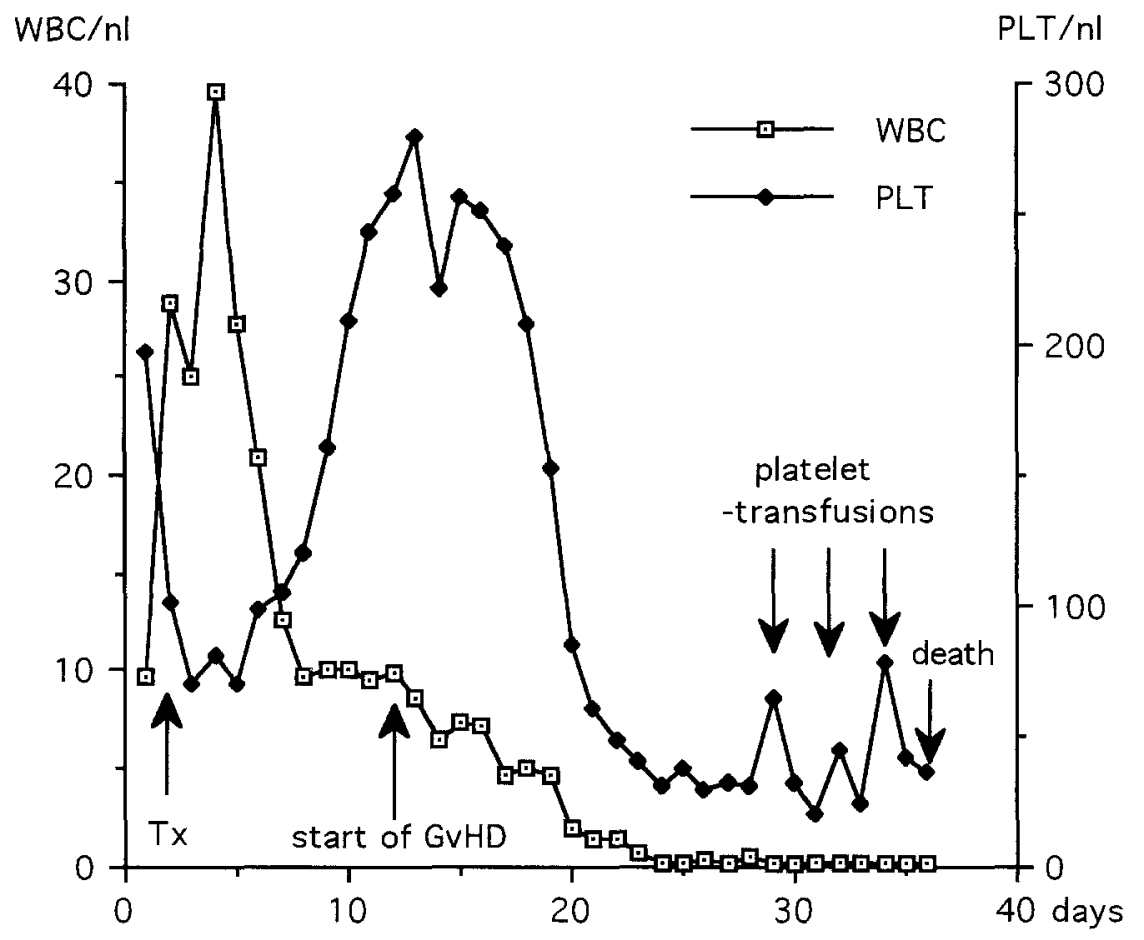

Fig. 1. Course of the number of white blood cells $(W B C)$ and platelets ( $P L T)$ during the development of acute GVHD.

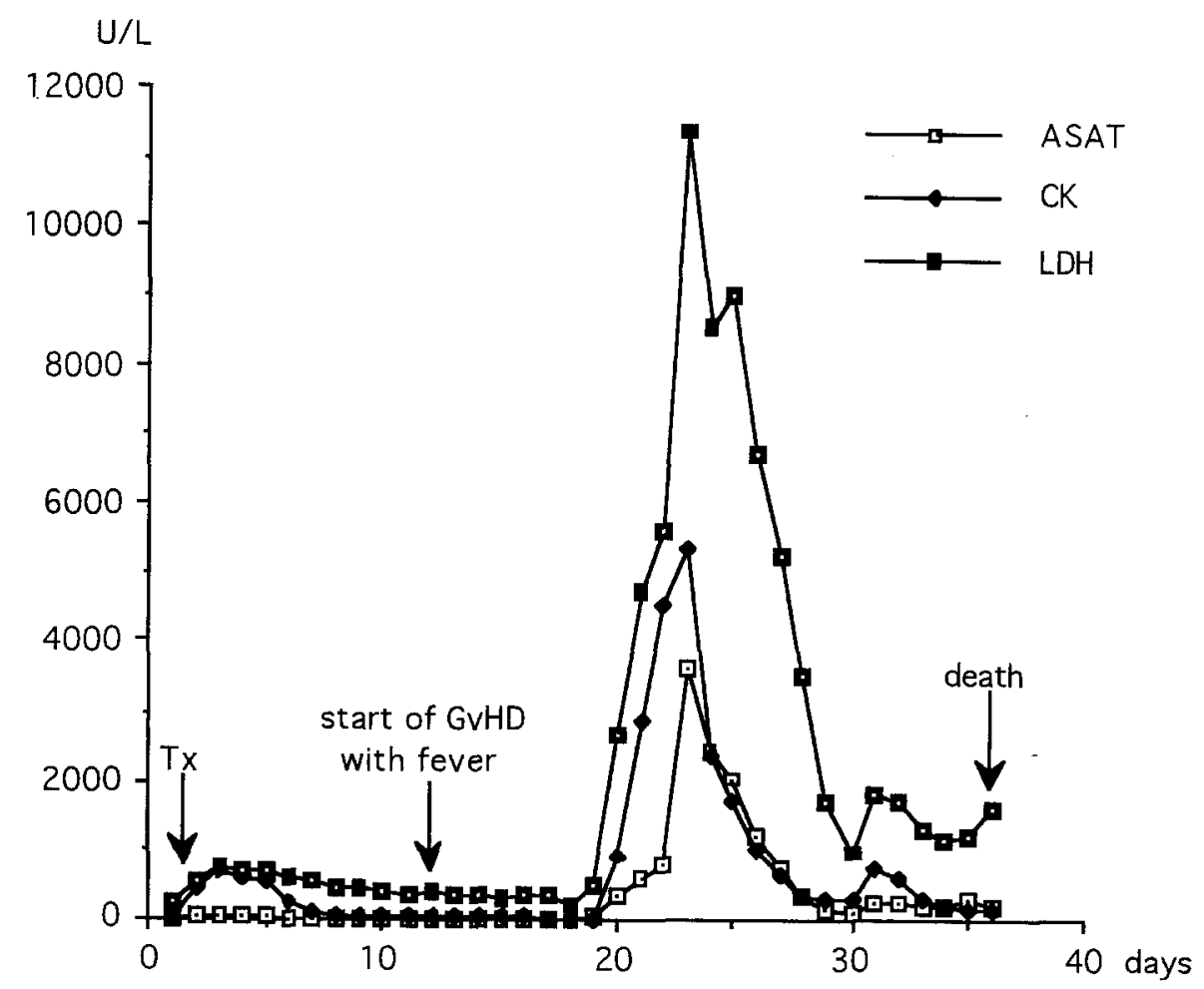

Fig. 2. Course of the amount of aspartate aminotransferase $(A S A T)$, creatine kinase $(C K)$, and lactate dehydrogenase $(L D H)$ of the patient during acute GVHD. 
nosis. If acute GVHD is clinically suspected, this may be confirmed immediately by skin biopsy and by HLA typing of the peripheral blood lymphocytes. Once GVHD is documented, aggressive cytolytic therapy to destroy donor lymphocytes seems to be the only therapeutic option.

\section{REFERENCES}

1. Prop J, Wildevuur CRH, Nieuwenhuis P. Acute graft-versushost disease after lung transplantation. Transplant Proc 1989; 21:2603-4.

2. Wood H, Higenbottam T, Joysey V, et al. Graft versus host disease after human heart-lung transplantation. In: Proceed- ings of the XIII International Congress of the Transplantation Society. San Francisco: August 19-24, 1990; p. 364.

3. Hunt BJ. Graft versus host disease in heart and/or lung transplantation. In: Rose ML, Yacoub MH, editors. Immunology of heart and lung transplantation. London: Arnold; 1993. p. 261-75.

4. Herman JG, Beschorner WE, Baugham KL, et al. Pseudograft-versus-host disease in heart and heart-lung recipients. Transplantation 1988;46:93-8.

5. Joysey V, Wood H, Ramsbottom S, et al. Lymphocyte chimaerism after solid organ transplantation. Transplant Proc 1992; 24:2519-22.

\title{
RUPTURE OF INFLOW CONDUITS IN THE TCI-HEARTMATE SYSTEM
}

\author{
Hans H. Scheld, MD, ${ }^{\mathrm{a}}$ Rasjid Soeparwata, MD, ${ }^{\mathrm{a}}$ Christof Schmid, MD, ${ }^{\mathrm{a}}$ Michael Loick, MD, ${ }^{\mathrm{b}}$ Michael Weyand, MD, \\ and Dieter Hammel, MD, ${ }^{a}$ Münster, Germany
}

Improved surgical techniques and sophisticated postoperative care have led to impressive long-term results for the implantable left ventricular assist device (LVAD) as a bridge to transplantation in patients with end-stage cardiac failure. However, all of the currently used assist devices are less than perfect, and only about $70 \%$ of patients supported with an LVAD eventually undergo transplantation. Apart from preoperative multiorgan failure, bleeding, thromboembolism, and infection still jeopardize the successful outcome and contribute to significant postoperative morbidity, because most of the patients have one or more of these adverse events. We report on a life-threatening complication, which has occurred in two of our six patients with the TCI-HeartMate system (Thermo Cardiosystems, Inc., Woburn, Mass.) and which seems to occur more often than expected. ${ }^{1}$

\section{Clinical summaries}

PATIENT 1. A 56-year-old male patient with end-stage ischemic heart disease was awaiting heart transplantation. Because of recurrent left ventricular decompensation and ongoing New York Heart Association class IV status, we decided to implant the TCI system as a bridge to trans-

From the Departments of Thoracic and Cardiovascular Surgery, ${ }^{\mathrm{a}}$ Anesthesia and Operative Intensive Care Medicine, ${ }^{b}$ Westfalian Wilhelms-University, Münster, Germany.

Received for publication Nov. 12, 1996; accepted for publication Jan. 15, 1997.

Address for reprints: Hans $H$. Scheld, MD, Klinik und Poliklinik für Thorax-, Herz- \& Gefäßchirurgie, Westfälische WilhelmsUniversität Münster, Albert-Schweitzer-Str. 33, 48129 Münster, Germany.

J Thorac Cardiovasc Surg 1997;114:287-9

Copyright (C) 1997 by Mosby-Year Book, Inc.

$0022-5223 / 97 \$ 5.00+0 \quad \mathbf{1 2 / 5 4 / 8 0 4 0 3}$ plantation. The patient fulfilled all criteria defined for patient selection. The LVAD was implanted with the heart beating, as has recently been described for the Novacor system (Baxter Healthcare Corp, Novacor Div., Oakland, Calif.). ${ }^{2}$ Initially, the postoperative course was uneventful except for placement of a chest tube for left-sided pleural effusion. The patient recovered well, with a pump output of 7 to $8 \mathrm{~L} / \mathrm{min}$, and organ function steadily improved. He was fully mobile when blood suddenly poured from the cutaneous exit of the drive line on postoperative day 22 . A chest $\mathrm{x}$-ray film revealed widening of the mediastinal structures but otherwise normal findings. After a sudden drop of the hemoglobin and hematocrit levels, the preperitoneal device pocket was reopened and massive clots poured out, suggesting severe bleeding. Immediate sternotomy was performed and extracorporeal circulation was instituted on an emergency basis. A transverse tear of 2 to $3 \mathrm{~mm}$ within the inflow conduit close to the proximal edge of the metallic cage support, protecting the Dacron conduit, became evident. Because of the massive blood loss, the left atrial filling pressure decreased and air was sucked into the lacerated Dacron tube of the inflow conduit. The LVAD was stopped immediately and the tear in the inflow conduit closed with felt-patch reinforced sutures, French glue, ${ }^{3,4}$ and double wrapping with a size 24 Dacron prosthesis. TCI LVAD support was reinstituted and no residual leakage was present. Despite meticulous deairing of the LVAD, massive cerebral air embolism caused brain death during the postoperative period. Pathologic examination confirmed rupture of the inflow conduit (Fig. 1).

PATIENT 2. A 35-year-old man with progressive deterioration as a result of dilative cardiomyopathy and recurrent ventricular arrhythmias (Lown IVb) underwent implantation of the TCI LVAD system. His condition had deteriorated steadily despite high-dose catecholamine ad- 